\title{
APRESENTAÇÃO
}

\section{Ensaios sobre Pierre Bourdieu}

\begin{abstract}
O verdadeiro respeito científico para com uma obra (e seu autor) consiste na discussão e na avaliação rigorosas e não na repetição sem fim dos conceitos, tiques de linguagem, estilo de escrita, raciocínios preestabelecidos etc. É preciso saber acordar alguns usos adormecidos desses conceitos, é preciso ousar levantar certas questões, autorizar-se a contradizer, refutar, complementar, matizar o pensamento de um autor. Nem rejeição brutal, nem repetição de epígono, mas dívidas $e$ críticas.
\end{abstract}

(Bernard Lahire)

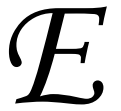

ducaẫo \& Sociedade apresenta neste número, com um pequeno dossiê, uma homenagem póstuma a Pierre Bourdieu, um dos maiores sociólogos do século XX. Interiorano de Denguin (Pirineus Atlânticos), nasceu em agosto de 1930; de origem modesta, seu pai foi funcionário dos correios: marcas presentes em toda sua trajetória intelectual e política.

Suas intervenções no espaço público datam do início de sua vida intelectual no final dos anos 50, quando produz seus primeiros trabalhos sobre transformações sociais na Algéria. Retornando à França em 1961 e dando continuidade à sua obra, faz da escola, política, cultura, artes, mídia, lazer e tantos outros setores da vida social o centro de suas preocupações intelectuais e políticas. Sua contribuição inovou e trouxe importantes debates às Ciências Sociais, particularmente à Sociologia da Educação. Intelectual engajado, sua trajetória acadêmica como sociólogo é profundamente marcada por questões objeto de suas atividades científicas e por oportunas intervenções políticas na vida social. A força do trabalho de Bourdieu, como afirma Philippe Cabin, é ter construído suas teorias a partir de múltiplas fontes teóricas: Emmanuel Kant, Karl Marx, Émile Durkheim, Max Weber, Marcel Mauss, Martin Heidegger, Gaston Bachelard, Thorsten Veblen, John Austin, Norbert Elias, Erving Goffman, Basil Bernstein, Claude Lévi-Strauss, Ludwig Wittgenstein e outros. 
Bourdieu foi fundador (janeiro de 1975) e diretor de publicação de Actes de la Recherche en Sciences Sociales, sua revista histórica. Dirigiu o periódico internacional dos livros Liber, inicialmente publicado como suplemento do Le Monde e depois assumido pela equipe de Actes. Desde 1996, integrou o conselho científico de Politix, revista das "ciências sociais do político" criada em 1968 no Departamento de Ciências Políticas da Universidade Paris I.

Com esse dossiê $\boldsymbol{E} \boldsymbol{\mathcal { S }} \boldsymbol{S}$ pretende iniciar, neste ano, um debate em torno do pensamento deste intelectual, com o objetivo de tematizar idéias suscitadas por sua obra.

Trajetória acadêmica do sociólogo contemporâneo

BOURDIEU, Pierre (1930-2002):

Liceu da cidade Pau (1941-1947)

Liceu Louis le Grand (1948-1951)

Escola Normal Superior (1951-1954)

Faculdade de Letras de Paris (1951-1954)

Professor no Liceu de Moulins (1954-1955)

Assistente na Faculdade de Letras de Alger, Algéria (1958-1960)

Assistente na Faculdade de Letras de Paris (1960-1961)

Mestre de Conferências na Faculdade de Letras de Lille (1961-1964)

Diretor de Estudos na Ecole des Hautes Etudes en Sciences Sociales (1964-2001)

Responsável por cursos na Ecole Normale Supérieure (1964-1984)

Diretor do Centre de Sociologie de l'Education et de la Culture (EHESSCNRS) (1964-1984)

Diretor da Coleção "Le Sens Comun" (Editions de Minuit) (19641992), "Líber" (Editions du Seuil) (1968)

Membro visitante no Institute for Advanced Studies (Princeton) (19721973)

Diretor da revista Actes de la Recherche en Sciences Sociales (1975-2002)

O Comitê Editorial da Educação \& Sociedade agradece a colaboração de Marie-Christine Riviere, que gentilmente forneceu o currículo atualizado de Bourdieu para a publicação neste dossiê. 
Consultor-editor da revista American Journal of Sociology (1975-2002) Professor Titular da cadeira de Sociologia do College de France (19822001)

Diretor do Centre de Sociologie Européenne (CSE) do College de France e da Ecole des Hautes Etudes en Sciences Sociales (1985-1998)

Diretor da Revue Internationale des Livres - Liber (1989-1998)

Doutor honoris causa da Universidade Livre de Berlin (1989); da Universidade Johann Wolfgang Goethe de Frankfurt (1996); da Universidade de Atenas (1996) e da Universidade de Joensuu (1999)

Membro da American Academy of Arts and Sciences

Membro do Conselho Científico do Max Planck Institut für Bildungsforschung (1974-1976)

Membro do Conselho Científico do Institut Maghreb-Europe (19912002)

Membro da Academia Europaea (1993-2002)

Membro estrangeiro da Academia Polonesa de Ciências (1994-2002) Medalha de Ouro do CNRS (1993), Erving Goffman Prize da Universidade da Californie-Berkeley (1996), Ernst-Bloch-Preis, da cidade de Ludwigshafen (1997), Huxley Memorial Medal (2000); Corresponding Fellow da British Academy (2001-2002)

Professor honorário do Collège de France (2002)

Diretor de Estudos (aposentado) na Ecole des Hautes Etudes en Sciences Sociales (2002) 